\title{
Utility of the novel bladder preservation therapy, BOAI-CDDP-radiation (OMC-regimen), for elderly patients with invasive bladder cancer
}

\author{
HARUHITO AZUMA ${ }^{1}$, TERUO INAMOTO ${ }^{1}$, NAOKAZU IBUKI ${ }^{1}$, TAKANOBU UBAI ${ }^{1}$, YATSUGU KOTAKE ${ }^{1}$, \\ KIYOSHI TAKAHARA ${ }^{1}$, SATOSHI KIYAMA ${ }^{1}$, HAYAHITO NOMI ${ }^{1}$, HIROSHI UEHARA ${ }^{1}$, \\ KAZUMASA KOMURA $^{1}$, KAZUHIRO YAMAMOTO ${ }^{2}$, YOSHIHUMI NARUMI ${ }^{2}$ and YOJI KATSUOKA ${ }^{1}$ \\ Departments of ${ }^{1}$ Urology and ${ }^{2}$ Radiology, Osaka Medical College, Takatsuki, Osaka 569-8686, Japan
}

Received August 17, 2010; Accepted October 15, 2010

DOI: 10.3892/ijo_00000819

\begin{abstract}
In this study, we investigated the novel bladder preservation therapy, the balloon-occluded arterial infusion (BOAI) of cisplatin/gemcitabine, concomitantly with hemodialysis, along with concurrent irradiation [the 'Osaka Medical College (OMC)-regimen'] in patients $>70$ years of age with muscle-invasive bladder cancer. Eighty-three such patients were assigned to receive either the OMC-regimen $(n=56)$ or cystectomy $(\mathrm{n}=27)$. The OMC-regimen patients who failed to achieve complete response (CR) underwent cystectomy, or secondary BOAI with gemcitabine $(1600 \mathrm{mg})$. The OMCregimen, which delivers an extremely high concentration of anti-cancer agent to the tumor site without systemic adverse effects, yielded CR in $>90 \%$ (39/43) of patients with locally invasive tumors $[70 \%(39 / 56)$ of all patients including those with $\mathrm{T} 4$ and $\mathrm{N}^{+}$disease]. None of the $\mathrm{CR}$ patients showed recurrence after a mean follow-up of 162 (range, 35-683) weeks, and 2 patients died of unrelated causes. The 5- and 12-year overall survival rates were 92.7 and $69.5 \%$ (vs. 59.6 and $20.9 \%$ for cystectomy; $\mathrm{P}<0.0092$ ), respectively, although the median age in the OMC-regimen group was significantly greater than that in the cystectomy group (median, 77; range, 70-98; vs. 74; 70-79; $\mathrm{p}<0.0001$ ). No patients suffered grade III or more severe toxicities. The oldest patient, aged 98 years,
\end{abstract}

Correspondence to: Dr Haruhito Azuma, Department of Urology, Osaka Medical College, Takatsuki, Osaka 569-8686, Japan E-mail: uro004@poh.osaka-med.ac.jp

Abbreviations: ANC, absolute neutrophil count; BOAI, balloonoccluded arterial infusion; CIS, carcinoma in situ; CTCAE, Common Terminology Criteria for Adverse Events; DSA, digital subtraction angiography; ECOG, Eastern Cooperative Oncology Group; HD, hemodialysis; Qu, quartile; RTOG, Radiation Therapy Oncology Group; TURBT, transurethral resection of bladder tumor; UC, urothelial carcinoma

Key words: balloon-occluded arterial infusion, hemodialysis, invasive bladder cancer, elderly patient successfully completed this therapy. The OMC-regimen is a useful bladder preservation strategy for elderly patients with locally invasive bladder cancer, not only for those for whom cystectomy has been indicated, but also for patients whose condition is not amenable to curative treatment and for whom palliation would otherwise seem the only option.

\section{Introduction}

The optimal initial treatment for muscle-invasive bladder cancer in elderly patients has been a subject of debate. Certain urologists or radiologists have recommended bladdersparing trimodality approaches with aggressive transurethral resection of the bladder tumor (TURBT) and radiochemotherapy, while others have advocated immediate cystectomy (1-5). Nielsen et al reviewed the records of 888 patients with transitional cell carcinoma who underwent radical cystectomy and pelvic lymphadenectomy for localized disease at 3 different institutions (6), and found that advanced age was independently and significantly associated with more pathologically advanced disease and poorer bladder-specific mortality after surgery. The actuarial 5-year overall survival rate of such patients $>70$ years of age has reportedly ranged from 35 to $60 \%(1-5,7,8)$. A highly effective, but non- or minimally-invasive therapy that conserves the bladder, is therefore required.

Combined treatment involving radical TURBT, chemotherapy and radiation therapy has been attempted as an alternative approach for patients who would otherwise require cystectomy. Since 1985, the Radiation Therapy Oncology Group (RTOG) has conducted 6 prospective clinical trials including 415 patients with T2-T4a muscle-invasive bladder cancer who were candidates for cystectomy (4,7-10). Among these patients, $>60 \%$ achieved a complete response $(\mathrm{CR})$, although the response rate differed according to the trial. However, none of the trials achieved a 5-year survival rate of $>52 \%$. Improvement of the survival rate could require a higher dosage, delivered specifically to the tumor, without causing systemic side-effects.

We developed a novel bladder preservation therapy [referred to hereafter as the 'Osaka Medical College (OMC)regimen'] involving the balloon-occluded arterial infusion 
(BOAI) of an anti-cancer agent and concurrent hemodialysis (HD). This allows the anti-cancer agent to accumulate at a high concentration at the site of the tumor while ensuring that the systemic concentration remains low, and this is then followed by radiation therapy. We found that $>90 \%$ of patients (39/43) with locally advanced urothelial bladder cancer who were treated in this way achieved $\mathrm{CR}$, and none developed recurrent disease or metastasis within a mean follow-up period of 162 weeks [range, 36-683 weeks; 1st to 3rd quartile $(\mathrm{Qu}), 84-215]$ after completion of the therapy. Herein, we describe this novel approach and its outcomes to date in comparison to total cystectomy, at our institution.

\section{Patients and methods}

Eligibility criteria. Eligible patients were elderly patients $>70$ years of age who had histologically confirmed stage T2, 3, or 4 muscle-invasive bladder cancer without distant metastasis. However, patients with pelvic lymph node metastasis, diagnosed by imaging studies, were also eligible. Imaging studies, including a chest computed tomography (CT) scan, abdominal/pelvic magnetic resonance imaging (MRI) and a CT scan, as well as bone scintigraphy, were performed prior to the start of therapy. All patients who received the OMCregimen had an absolute neutrophil count (ANC) of $1,500 / \mu 1$, a platelet count of $100,000 / \mu 1$, creatinine levels of $3 \mathrm{mg} / \mathrm{dl}$, a bilirubin level 3-fold the institutional upper limit of the normal range, an AST level 4-fold the institutional upper limit of the normal range, an Eastern Cooperative Oncology Group (ECOG) performance status of $0-2$, and no prior radiotherapy or systemic therapy for bladder cancer. The study was reviewed and approved by the Institutional Review Board of the OMC. Patients were informed of the investigational nature of the study and provided written informed consent prior to enrollment.

Study design and treatment. Prior to study entry, patients underwent complete TURBT at our institution in order to establish the diagnosis. We primarily recommended total cystectomy when surgery was feasible. However, the OMCregimen was offered as another treatment option whenever total cystectomy was not feasible due to advanced age, performance status, or other reasons. Patients were assigned to receive the OMC-regimen at 4-5 weeks after TURBT to allow for adequate healing.

Assessability, toxicity and response criteria. Pre-treatment evaluation included a complete history and physical examination, performance status assessment, complete differential blood cell count, electrolyte, blood urea nitrogen (BUN) and serum creatinine levels, liver function parameters, and appropriate imaging studies to assess the extent of disease. During treatment, patients were observed weekly at our institution, where their weight was recorded and toxicity was monitored using the National Cancer Institute's Common Terminology Criteria for Adverse Events v4.0 (CTCAE). At 6 weeks, patients underwent repeat transurethral resection of the site of the original tumor, ultrasound-guided whole-layer biopsy and urine cytology, as well as an MRI and CT scan of the pelvis, and were evaluated for their response to the therapy. CR was defined as complete disappearance of all measurable and evaluable disease. Duration of response was defined as the period from the documentation of the response until evidence of disease recurrence. Survival was the period from study entry until patient death. Patients who achieved CR were observed using our follow-up protocol. However, any evidence of residual tumor in the bladder was deemed as treatment failure, and such patients were primarily advised to undergo total cystectomy when possible, or otherwise to undergo secondary BOAI with a higher dosage of cisplatin (CDDP) or gemcitabine (1600 mg), as a salvage therapy. Patients who were found to have only a superficial amount of remaining tumor underwent intravesical injection of Bacillus Calmette-Guérin.

Follow-up. All patients were followed-up with monthly urine cytology, together with cystoscopy, biopsy and imaging studies, every 3 months for 2 years, including a chest CT scan, an abdominal/pelvic MRI and CT scan, as well as bone scintigraphy, and then at 6-month intervals thereafter.

Statistics. Simple as well as multiple regression analyses were conducted to evaluate the significance of the following variables as risk factors of treatment failure: T-stage, tumor pathology [urothelial carcioma (UC) vs. non-UC)], patient performance status, gender, age and the amount of CDDP administered. Differences of $\mathrm{P}<0.05$ were considered to be statistically significant. The life-table probabilities of overall and progression-free survival were determined using KaplanMeier analysis and the log-rank test. Cox proportional hazards regression analysis was conducted to assess the associations of each factor, including T-stage, tumor pathology (UC vs. non-UC), patient performance status, gender, age and the amount of CDDP administered. Differences of $\mathrm{P}<0.05$ were considered to be statistically significant.

\section{Results}

Patient characteristics. Between 1988 and 2009, 56 patients (37 males and 19 females) were treated with the OMCregimen, and 27 (25 males and 2 females) underwent radical cystectomy. The characteristics of the patients in these 2 treatment groups are shown in Table I. For pre-operative clinical staging, we used a simplified form of the 2002 TNM classification for staging bladder tumors as Tis, T1, T2, T3 and T4 (11). In order to make a valid comparison, preoperative clinical staging and not the pathological stage after cystectomy, was used to compare the 2 treatment groups, thus avoiding stage migration that can occur after pathological staging (12). The distribution of clinical stage and histological grade is shown in Table I.

\section{Treatment details}

OMC-regimen group. Patients assigned to the OMC-regimen group underwent complete TURBT at our institution in order to establish the diagnosis. They were then scheduled to receive the OMC regimen 4-5 weeks after TURBT to allow for adequate healing. We administered 100, 200, or $300 \mathrm{mg}$ of CDDP as a single bolus according to the criteria described in Table II. 
Table I. Characteristics of patients in the 2 groups.

\begin{tabular}{|c|c|c|c|}
\hline Characteristics & $\begin{array}{l}\text { OMC } \\
\text { regimen }\end{array}$ & $\begin{array}{c}\text { Total } \\
\text { cystectomy }\end{array}$ & P-value \\
\hline \multicolumn{4}{|l|}{ Age } \\
\hline Median (range) in years & $77(70-98)$ & $74 \quad(70-79)$ & 0.0021 \\
\hline \multicolumn{4}{|l|}{ Gender } \\
\hline Male (\%) & $37(66.1 \%)$ & $25(92.6 \%)$ & 0.0182 \\
\hline Female $(\%)$ & $19(33.9 \%)$ & $2 \quad(7.4 \%)$ & \\
\hline \multicolumn{4}{|l|}{ Clinical stage } \\
\hline \multicolumn{4}{|l|}{ T-stage } \\
\hline $\mathrm{Cis}$ & $0 \quad(0 \%)$ & $1 \quad(3.7 \%)$ & NS \\
\hline $\mathrm{T}$ & $15(26.8 \%)$ & $17(63.0 \%)$ & 0.0021 \\
\hline T3 & $30(53.6 \%)$ & $9(33.3 \%)$ & NS \\
\hline $\mathrm{T} 4$ & $11(19.6 \%)$ & $(0 \%)$ & NS \\
\hline \multicolumn{4}{|l|}{$\mathrm{N}$-stage } \\
\hline No & $86(89.6 \%)$ & $96 \quad(100 \%)$ & NS \\
\hline N1 & $10(10.4 \%)$ & $(0 \%)$ & \\
\hline \multicolumn{4}{|l|}{ Tumor histology } \\
\hline \multicolumn{4}{|l|}{$\mathrm{UC}$} \\
\hline $\mathrm{G} 2$ & $5(8.9 \%)$ & $32(33.3 \%)$ & 0.0208 \\
\hline G3 & $45(80.4 \%)$ & $55(57.3 \%)$ & 0.0004 \\
\hline \multicolumn{4}{|l|}{ Others } \\
\hline Adenocarcinoma & $5(8.9 \%)$ & $(0 \%)$ & NS \\
\hline Squamous cell carcinoma & $0 \quad(0 \%)$ & $1 \quad(3.7 \%)$ & NS \\
\hline Choriocarcinoma & $1(1.8 \%)$ & $(0 \%)$ & NS \\
\hline \multicolumn{4}{|l|}{ ECOG performance status } \\
\hline 0 & $13(23.2 \%)$ & $13(48.14 \%)$ & 0.0244 \\
\hline 1 & $28(50.0 \%)$ & $7(25.93 \%)$ & 0.0411 \\
\hline 2 & $14(18.8 \%)$ & $7(25.93 \%)$ & NS \\
\hline 3 & $1(1.8 \%)$ & $(0 \%)$ & NS \\
\hline
\end{tabular}

For the intra-arterial infusion procedure, we used an intraarterial catheter equipped with 2 occlusion balloons (size: 6 Fr., M6F-28-70-TBSB4-ST, Clinical Supply, Tokyo, Japan). The catheter was introduced into the posterior trunk of the internal iliac artery through the femoral arterial approach, and after the distal balloon had passed through the furcation of the anterior trunk of the internal iliac artery, both the distal and proximal balloons were inflated and immobilized, so that the anterior trunk of the internal iliac artery, which lies upstream of the target vessels (the 'vesical arteries'), was isolated between the balloons. At this time, using digital subtraction angiography (DSA), it was confirmed that the injected agent had not entered the superior gluteal artery and that there was no back-flow into the internal iliac artery, while the tumor was markedly stained due to the active flow of injected contrast medium into the urinary bladder. Fig. 1 illustrates the extra-corporeal circuit used in the treatment, and Fig. 2 presents DSA images of the bilateral common iliac arteries before and after balloon occlusion. Various amounts of CDDP $(100,200$, or $300 \mathrm{mg})$ were locally infused through the catheter over a $1-\mathrm{h}$ period (Table I). Simultaneously, HD was performed via 2 double-lumen catheters (size: 12 Fr., Argyle ${ }^{\circledR}$, Tyco Healthcare, Tokyo, Japan) placed in the bilateral common iliac veins for $2 \mathrm{~h}$ after the start of arterial
Table II. Criteria for the administration of CDDP

In the initially enrolled 11 patients

$100 \mathrm{mg}$ Renal function $(\mathrm{sCr} \geq 1.3 \mathrm{mg} / \mathrm{dl}$ ) or age, $>75$ years

$200 \mathrm{mg} \quad$ Renal function ( $\mathrm{sCr}<1.3 \mathrm{mg} / \mathrm{dl}$ ) with age, $60-74$ years and T-stage, $\mathrm{T} 2$ or $\mathrm{T} 3$

$300 \mathrm{mg} \quad$ Renal function $(\mathrm{sCr}<1.3 \mathrm{mg} / \mathrm{dl}$ ) with age, $<60$ years or T-stage, T4

In the last 45 patients

$100 \mathrm{mg} \quad$ All patients

sCr, serum creatinine.

infusion. The catheters were connected to a hollow-fiber dialyzer (APS150, Asahi, Tokyo, Japan) with a membrane area of $1-1.5 \mathrm{~m}^{2}$ according to the weight of each patient. The blood flow rate was $180-250 \mathrm{ml} / \mathrm{min}$ and the HD-fluid flow rate was $500 \mathrm{ml} / \mathrm{min}$.

Radiation therapy was administered to the whole pelvis using a CT-planned 3-dimensional conformal technique at a total of 60.4:50.4 Gy (1.8 Gy/day x 28 days) which was followed by 10 Gy ( 2 Gy/day x 5 days) of local irradiation to the bladder. Patients were treated with an empty bladder. The planned target volume for the bladder included the gross target volume (bladder plus any extravesical tumor) with a 1-cm expansion. At 6 weeks, patients underwent repeat transurethral resection of the site of the original tumor, an ultrasound-guided whole-layer biopsy and urine cytology, as well as an MRI and CT scan of the pelvis, and the response to this therapy was then evaluated.

Radical cystectomy group. Among the 27 patients in the radical cystectomy group, 13 patients underwent ureterocutaneostomy, 8 underwent ileal conduit formation, 4 underwent continent urinary diversion with ileal-neobladder formation (Hartmann's method), 1 unerwent Indiana pouch formation, and the remaining 1 patient underwent ureterosigmoidostomy performed at the time of radical cystectomy. A standard pelvic lymphadenectomy was performed in 21 patients, 5 underwent iliac sampling, and 1 patient was not studied in sufficient detail to allow for the assessment of the level of lymph node dissection. As not all of the histology reports mentioned the number of lymph nodes examined, it was not possible to precisely evaluate the extent of dissection. There were no significant differences in cause-specific or overall survival between the patients who underwent nodal dissection and those who did not. Urethrectomy was performed in 2 patients at the time of radical cystectomy due to the presence of extensive carcinoma in situ (CIS) or multifocal bladder tumors.

Response to the OMC-regimen. Table III summarizes the treatment response, duration of response and patient characteristics, including $\mathrm{T}$ - and $\mathrm{N}$-stage, tumor histology (UC vs. non-UC), patient performance status, gender, age, and the amount of CDDP administered. Overall, 39 of the 56 


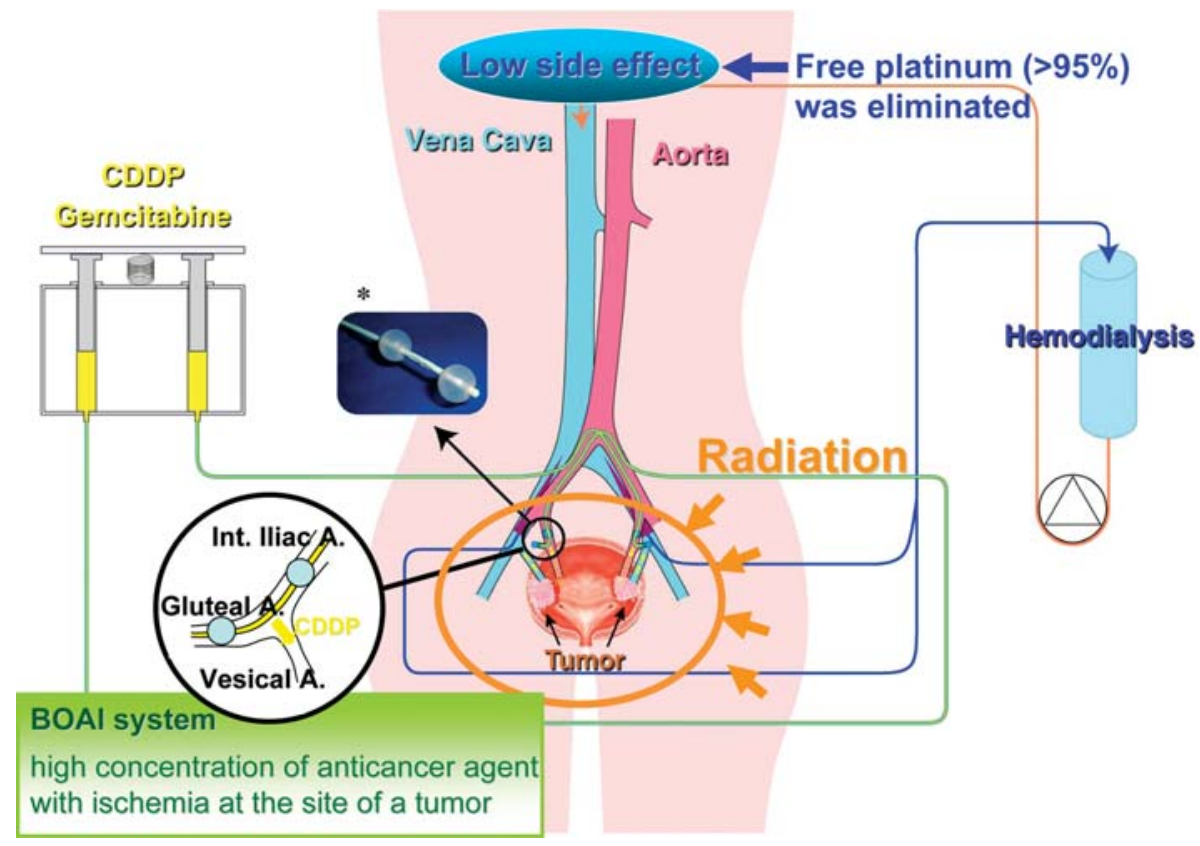

Figure 1. Schema of the OMC-regimen (HD-BOAI-CDDP/gemcitabine with radiation). The extra-corporeal circuit allowed for the balloon-occluded intraarterial infusion of CDDP/gemcitabine concurrently with HD. Through the femoral arterial approach, an intra-arterial catheter equipped with two occlusion balloons was introduced into the posterior trunk of the internal iliac artery on each side. Both the distal and proximal balloons were inflated and immobilized at a position allowing the 'vesical arteries' to be isolated between the balloons. After confirming by angiography that the catheter was in the right position, various amounts of CDDP $(100,200$, or $300 \mathrm{mg})$, or gemcitabine (1600 mg) were infused through the side holes of the catheter between the inflated balloons over a 1-h period. Simultaneously, HD was performed via double-lumen catheters placed in the bilateral common iliac vein for $2 \mathrm{~h}$ after the start of arterial infusion. The panel marked with an asterisk shows an image of the intra-arterial catheter (M6F-28-70-TBSB4-ST, Clinical Supply), which is made of polyethylene, 6-Fr. in size, and equipped with 2 occlusion balloons separated by a distance of $40 \mathrm{~mm}$. It has side holes between the balloons enabling the injection of contrast medium or anti-cancer agent.
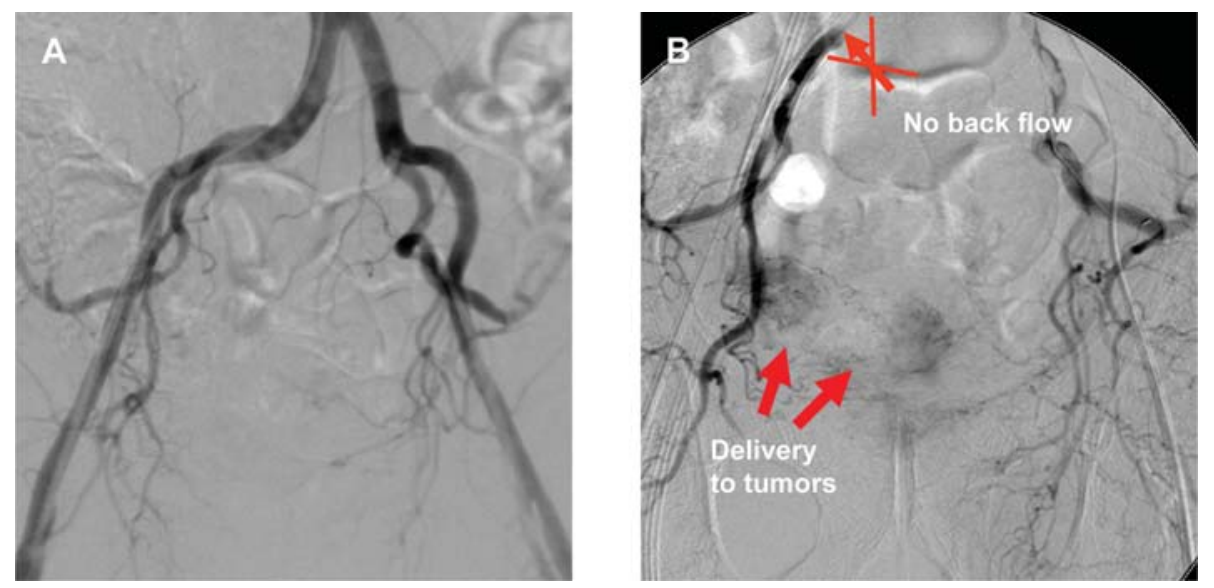

Figure 2. Bilateral common iliac arteriography before (A) and after (B) balloon occlusion. We ensured that there was no back-flow of contrast medium into the internal iliac artery, and that the anti-cancer agent was delivered to the urinary bladder, especially to the tumor site.

patients $[76,95 \%$ confidence interval $(\mathrm{CI}), 66.3-84.2 \%]$ achieved CR as defined by the absence of persistent disease revealed by cystoscopy, biopsy and urine cytology after therapy (Table III). All patients with CR were able to retain their urinary bladder with no evidence of recurrent disease or distant metastasis within a mean follow-up period of 162 weeks (range, 36-683 weeks; 1st to 3rd Qu, 84-215 weeks) from the completion of therapy, while 2 patients died of unrelated causes. All patients who achieved CR had the histological characteristics of locally invasive tumors (stage T2 or 3 node-negative) and UC. Fig. 3 shows horizontal and coronal MRI images obtained before and after treatment.

In contrast to the high $\mathrm{CR}$ induction ratio in patients with locally invasive UC tumors, all patients with lymph node involvement, stage T4 tumors and/or tumors besides UC, failed to achieve CR after the treatment. Table IV shows the results of simple and multiple regression analyses of the risk factors for treatment failure, the independent variables being 
Table III. Response at 3 months after treatment, and current outcome.

\begin{tabular}{|c|c|c|c|c|c|c|c|c|c|c|c|c|}
\hline \multirow[b]{2}{*}{ Categories } & \multicolumn{3}{|c|}{ CR } & \multicolumn{3}{|c|}{ PR } & \multicolumn{3}{|c|}{ SD } & \multicolumn{3}{|c|}{ PD } \\
\hline & No. & $\%$ & $95 \% \mathrm{CI}$ & No. & $\%$ & $95 \% \mathrm{CI}$ & No. & $\%$ & $95 \% \mathrm{CI}$ & No. & $\%$ & $95 \% \mathrm{CI}$ \\
\hline Total number of patients & 39 & 69.6 & $55.9-81.2$ & 4 & 7.14 & $1.98-17.3$ & 6 & 10.7 & $4.03-21.9$ & 7 & 12.5 & $5.18-24.1$ \\
\hline \multicolumn{13}{|l|}{ Duration of response } \\
\hline Mean (range) in weeks & \multicolumn{3}{|c|}{$162(36-683)$} & \multicolumn{3}{|c|}{$67(39-96)$} & \multicolumn{3}{|c|}{$24(15-36)$} & & \multicolumn{2}{|c|}{0} \\
\hline 1st to $3 \mathrm{rd} \mathrm{Qu}$ in weeks & \multicolumn{3}{|c|}{$84-215$} & \multicolumn{3}{|c|}{$54-81$} & \multicolumn{3}{|c|}{$18-29$} & & \multicolumn{2}{|c|}{0} \\
\hline Recurrence & 0 & 0 & $0-9.03$ & 1 & 25 & $0.63-80.6$ & 6 & 100 & $54.1-100$ & & & \\
\hline Death & 2 & 5.13 & $0.63-17.3$ & 0 & 0 & $0-60.2$ & 5 & 83.3 & $35.9-99.6$ & 6 & 85.7 & 42.1-99.6 \\
\hline Age, mean (range) in years & \multicolumn{3}{|c|}{$77(71-85)$} & \multicolumn{3}{|c|}{$77(72-82)$} & \multicolumn{3}{|c|}{$78(70-98)$} & \multicolumn{3}{|c|}{$73(71-81)$} \\
\hline \multicolumn{13}{|l|}{ Gender } \\
\hline Female & 13 & 33.3 & $19.1-50.2$ & 1 & 25 & $0.63-80.6$ & 2 & 33.3 & $4.33-77.7$ & 3 & 42.9 & $9.90-81.6$ \\
\hline \multicolumn{13}{|l|}{$\mathrm{T}$ stage } \\
\hline 2 & 15 & 38.5 & $23.4-55.4$ & 0 & 0 & $0-60.2$ & 0 & 0 & $0-45.9$ & 0 & 0 & $0-41.0$ \\
\hline 3 & 24 & 61.5 & $44.6-76.6$ & 2 & 50 & $6.76-93.2$ & 2 & 33.3 & $4.33-77.7$ & 2 & 28.6 & $3.67-71.0$ \\
\hline 4 & 0 & 0 & $0-9.03$ & 2 & 50 & $6.76-93.2$ & 4 & 66.7 & $22.2-95.7$ & 5 & 71.4 & $29.0-96.3$ \\
\hline \multicolumn{13}{|l|}{$\mathrm{N}$ stage } \\
\hline $\mathrm{N}^{-}$ & 39 & 100 & $91.0-100$ & 4 & 100 & $39.7-100$ & 2 & 33.3 & $4.33-77.7$ & 5 & 71.4 & $29.0-96.3$ \\
\hline $\mathrm{N}^{+}$ & 0 & 0 & $0-9.03$ & 0 & 0 & $0-60.2$ & 4 & 66.7 & $22.2-95.7$ & 2 & 28.6 & $3.67-71.0$ \\
\hline \multicolumn{13}{|l|}{ Histology } \\
\hline $\mathrm{UC}$ & 38 & 97.4 & $86.5-99.9$ & 4 & 100 & $39.7-100$ & 4 & 66.7 & $22.2-95.7$ & 3 & 42.9 & $9.90-81.6$ \\
\hline Non-UC & 1 & 2.6 & $0.06-13.5$ & 0 & 0 & $0-60.2$ & 2 & 33.3 & $4.33-77.7$ & 4 & 57.1 & $18.4-90.1$ \\
\hline 1 & 20 & 51.3 & $34.8-67.6$ & 2 & 50 & $6.76-93.2$ & 4 & 66.7 & $22.2-95.7$ & 2 & 28.6 & $3.67-71.0$ \\
\hline 2 & 9 & 23.1 & $11.1-39.3$ & 2 & 50 & $6.76-93.2$ & 1 & 16.7 & $0.42-64.1$ & 2 & 28.6 & $3.67-71.0$ \\
\hline 3 & 1 & 2.6 & $0.06-13.5$ & 0 & 0 & $0-60.2$ & 0 & 0 & $0-45.9$ & 0 & 0 & $0-41.0$ \\
\hline \multicolumn{13}{|l|}{ CDDP in $\mathrm{mg}$} \\
\hline 100 & 37 & 94.9 & $82.7-99.4$ & 4 & 100 & $39.7-100$ & 4 & 66.7 & $22.2-95.7$ & 6 & 85.7 & $42.1-99.6$ \\
\hline 200 & 1 & 2.6 & $0.06-13.5$ & 0 & 0 & $0-60.2$ & 0 & 0 & $0-45.9$ & 1 & 14.3 & $0.36-57.9$ \\
\hline 300 & 1 & 2.6 & $0.06-13.5$ & 0 & 0 & $0-60.2$ & 2 & 33.3 & $4.33-77.7$ & 0 & 0 & $0-41.0$ \\
\hline Gemcitabine & 0 & 0 & $0-9.03$ & 2 & 50 & $6.76-93.2$ & 1 & 16.7 & $0.42-64.1$ & 1 & 14.3 & $0.36-57.9$ \\
\hline
\end{tabular}

$\mathrm{CR}$, complete response; $\mathrm{PR}$, partial response; $\mathrm{SD}$, stable disease; $\mathrm{PD}$, progressive disease.

T- and N-stage, histology, age, gender, performance status and the amount of CDDP administered. As shown simple logistics analysis, stage T4, lymph node involvement and histological type (non-UC), were independent statistically significant risk factors for treatment failure (Table IV).

Effect of salvage therapy for remaining cancer. Total cystectomy was recommended as a salvage therapy for patients with any remaining invasive tumor without lymph node involvement. However, most patients were ineligible for this option due to age, performance status or the presence of other disease, such as myocardial infarction and liver dysfunction. As a salvage therpay, these patients received secondary BOAI with gemcitabine $(1600 \mathrm{mg})$, which can also be eliminated by HD, or they requested no further treatment. Four patients received secondary BOAI with gemcitabine, 1 achieved partial response with no evidence of recurrent disease or distant metastasis at the 1-year follow-up point, while 3 other patients showed progressive disease or disease recurrence after a period of stable disease.

Post-operative clinical course after radical cystectomy. Overall, 11 of the 27 patients $(40.7,95 \%$ CI, 22.4-61.2\%) were found to have disease recurrence, of whom $>90 \%$ (10/11, 91, 95\% CI, 58.7-99.8\%) subsequently died. The influence of various factors, including age, gender, performance status ( 2 vs. 0 or 1 ), chemotherapy (neoadjuvant or adjuvant), pre-treatment clinical $\mathrm{T}$-stage, pathological $\mathrm{T}$ stage (pT4 vs. others), $\mathrm{N}$ stage and histology (non-UC vs. $\mathrm{UC}$ ) on disease recurrence, were investigated by simple and 

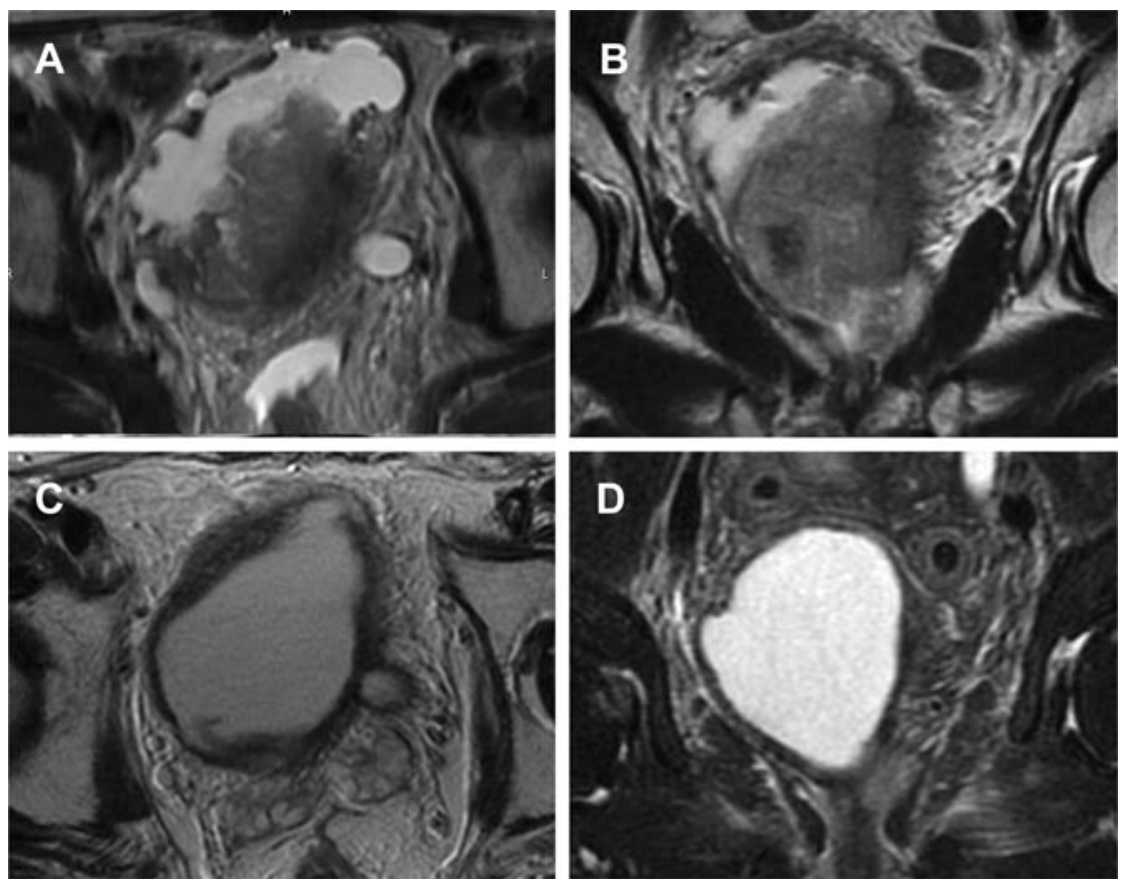

Figure 3. MRI before (A and B) and after (C and D) the treatment. The horizontal (A) and coronal (B) MRI slices before the treatment show bulky tumors, which occupy more than half of the bladder cavity. The treatment with the OMC-regimen induced CR, as confirmed by all imaging studies $(\mathrm{C}$, horizontal and $\mathrm{D}$, coronal), which show complete disappearance of the tumors and the intact mucosa and muscle layer at 10 weeks after completion of the therapy.

Table IV. Risk factors for treatment failure in the OMCregimen group.

\begin{tabular}{|c|c|c|c|c|}
\hline \multirow[b]{2}{*}{ Category } & \multicolumn{2}{|c|}{ Univariate } & \multicolumn{2}{|c|}{ Multivariate } \\
\hline & Odds ratio & P-value & Odds ratio & P-value \\
\hline \multicolumn{5}{|l|}{ T-stage } \\
\hline T4 vs. T2-3 & 6.500 & $<0.0001$ & No value & No value \\
\hline \multicolumn{5}{|l|}{$\mathrm{N}$-stage } \\
\hline $\mathrm{N}^{+}$vs. $\mathrm{N}^{-}$ & 3.545 & $<0.0001$ & No value & No value \\
\hline \multicolumn{5}{|l|}{ Histology } \\
\hline Non-UC vs. UC & 20.83 & 0.0075 & 21.74 & 0.0117 \\
\hline \multicolumn{5}{|l|}{ Performance status } \\
\hline 2 vs. 0 or 1 & 1.208 & 0.7697 & 1.080 & 0.9230 \\
\hline \multicolumn{5}{|l|}{ Gender } \\
\hline Male vs. female & 1.091 & 0.8867 & 0.937 & 0.9278 \\
\hline \multicolumn{5}{|l|}{ Age } \\
\hline Cont. variable & 1.008 & 0.8909 & 1.036 & 0.6150 \\
\hline \multicolumn{5}{|c|}{ Amount of CDDP (mg) } \\
\hline 100 vs. 200 or 300 & 3.964 & 0.1536 & 1.911 & 0.5888 \\
\hline
\end{tabular}

Cont. variable, continuous variable.

multiple regression analyses. As shown by simple or multiple logistic analyses, no factors were independent statistically significant risk factors for disease recurrence (Table V).

Comparison of survival between the 2 groups

Overall survival. Overall survival was improved in the OMC-regimen group, with 5- and 12-year survival rates of 76.8 and $57.6 \%$, respectively compared to 59.6 and $20.9 \%$ in the cystectomy group, despite of no statistical significance
Table V. Risk factors for disease recurrence in the cystectomy group.

\begin{tabular}{|c|c|c|c|c|}
\hline \multirow[b]{2}{*}{ Category } & \multicolumn{2}{|c|}{ Univariate } & \multicolumn{2}{|c|}{ Multivariate } \\
\hline & Odds ratio & $\mathrm{P}$-value & Odds ratio & P-value \\
\hline \multicolumn{5}{|l|}{ Age } \\
\hline Cont. variable & 1.119 & 0.4589 & 1.217 & 0.4136 \\
\hline \multicolumn{5}{|l|}{ Gender } \\
\hline Male vs. female & 1.038 & 0.9789 & $6.088 \mathrm{E}-9$ & 0.9965 \\
\hline \multicolumn{5}{|l|}{ Performance status } \\
\hline 2 vs. $0-1$ & 2.476 & 0.3116 & 8.763 & 0.0719 \\
\hline \multicolumn{5}{|l|}{ Chemotherapy } \\
\hline$(+)$ vs. $(-)$ & 1.257 & 0.7820 & 1.623 & 0.6914 \\
\hline \multicolumn{5}{|l|}{ Clinical T-stage } \\
\hline T3 vs. T2 & 2.500 & 0.2734 & 1.092 & 0.9521 \\
\hline \multicolumn{5}{|c|}{ Pathological T-stage } \\
\hline pT4 vs. pT1-3 & 3.333 & 0.3526 & 13.941 & 0.2722 \\
\hline \multicolumn{5}{|c|}{ Pathological N-stage } \\
\hline $\mathrm{N}^{+}$vs. $\mathrm{N}^{-}$ & 1.556 & 0.6845 & 6.317 & 0.2314 \\
\hline \multicolumn{5}{|l|}{ Histology } \\
\hline Non-UC vs. UC & 318982 & 0.9774 & 1642 & 0.9978 \\
\hline
\end{tabular}

( $\mathrm{p}=0.2176$; Fig. 4A). However, overall survival was significantly greater in the OMC-regimen group, with 5- and 12year survival rates of 92.7 and $69.5 \%$, respectively (vs. 59.6 and $20.9 \%$ in the cystectomy group; log-rank test, $\mathrm{p}=0.0092$; Fig. 4B), when the results were compared under the same conditions by matching the clinical stage, and by excluding 
A

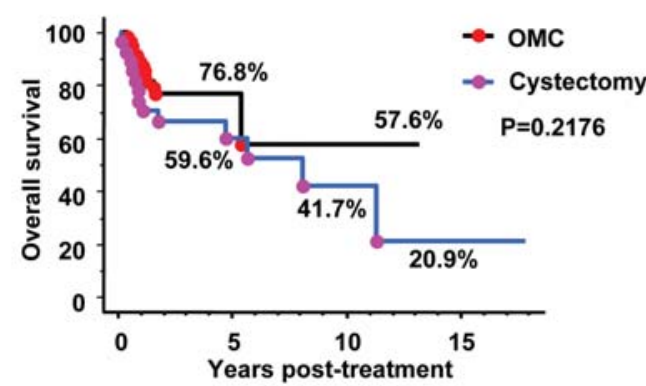

C

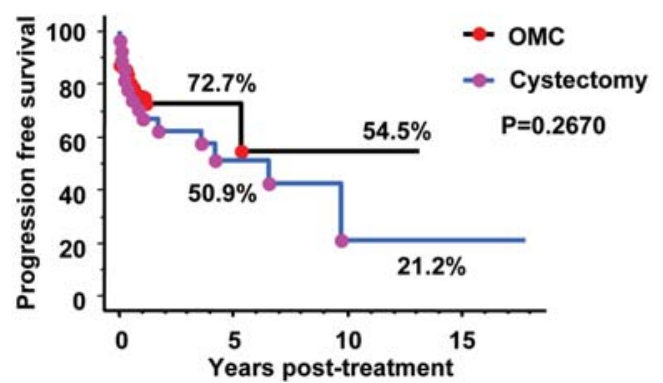

B

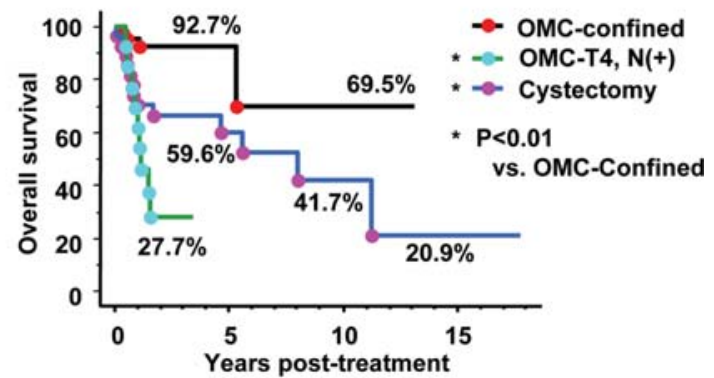

D

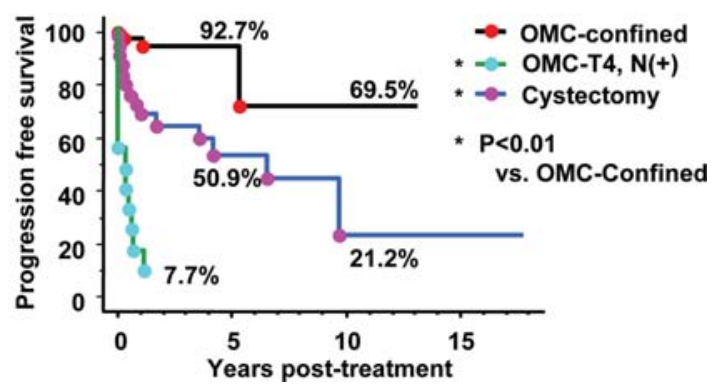

Figure 4. Kaplan-Meier curves for overall (A and B) and progression-free survival (C and D) in each group. (A) Comparison of the overall survival between the OMC-regimen and cystectomy groups. (B) Comparison of the overall survival among the 2 OMC-regimen subgroups $\left(\mathrm{OMC}-\mathrm{Confined}\right.$ and $\left.\mathrm{OMC}-\mathrm{T} 4-\mathrm{N}^{+}\right)$, and the cystectomy group. The OMC-confined group comprised of patients with organ-confined disease, and the OMC-T4- $\mathrm{N}^{+}$group comprised of patients with stage $\mathrm{T} 4$ or $\mathrm{N}^{+}$disease. (C) Comparison of progression-free survival between the OMC-regimen and cystectomy groups. (D) Comparison of progressionfree survival among the OMC-confined and OMC-T4-N+ $\mathrm{N}^{+}$subgroups and the cystectomy group, respectively.

patients with stage T4 tumors and/or lymph node metastasis from the OMC-regimen group. The Kaplan-Meier curves used for the comparison of the overall survival among the 2 OMC-regimen subgroups (OMC-confined, comprising of patients with organ-confined disease, and OMC-T4- $\mathrm{N}^{+}$, comprising of patients with stage $\mathrm{T} 4$ or $\mathrm{N}^{+}$disease; OMCconfined vs. OMC-T4-N+, p<0.0001) and the cystectomy group are shown in Fig. 4B.

Progresion-free survival. The progression-free survival ratio of the OMC-regimen group was not inferior to that of the cystectomy group, the 5- and 12-year survival rates being 72.7 and $54.5 \%$, respectively (vs. 50.9 and $21.2 \%$; log-rank test, $\mathrm{p}=0.2670$; Fig. 4C). Moreover, the progression-free survival was significantly greater in the OMC-regimen compared to the cystectomy group in patients with organconfined disease with 5-, and 12-year survival rates of 92.7 and $69.5 \%$, respectively (vs. 50.9 and $21.2 \%$; log-rank test, $\mathrm{p}=0.0018$; Fig. 4D) After completion of the OMC-regimen, all patients survived without disease progression and were followed-up, showing a mean survival of 162 weeks (range 36-683 weeks, 1st to 3rd Qu, 84-215 weeks). In contrast, all but one patient with $\mathrm{T} 4$ tumors or lymph node metastasis showed disease progression within 2 years after the treatment with 2-year progression-free survival rates of $7.7 \%$ (vs. OMC-confined; $\mathrm{p}<0.0001)$. The Kaplan-Meier curves used for the comparison of progression-free survival among the 2 OMC-regimen subgroups (OMC-confined and OMC-T4-N+ ${ }^{+}$) and the cystectomy group are shown in Fig. 4D.
Predictors of overall and progression-free survival selected using univariate and multivariate analyses in the 2 groups $O M C$-regimen group. We investigated the significance of each factor, including pre-treatment T-stage, lymph node involvement, tumor pathology (non-UC vs. UC), patient performance status (2 vs. 0-1), gender, age and the amount of CDDP administered (100 vs. 200-300 mg), as a predictor of progression-free and overall survival using the Cox regression model. As shown in Table VI, univariate Cox regression analysis selected stage T4, lymph node metastasis, and tumor pathology (non-UC) as significant factors affecting both disease progression and overall survival. Moreover, multivariate Cox regression analysis selected stage $\mathrm{T} 4$ and lymph node metastasis as significant factors affecting disease progression. Fig. 5 shows the Kaplan-Meier curves for the overall and progression-free survival of patients at each clinical stage (Fig. 5A and B) and for each histological type (Fig. 5C and D), respectively. Both the overall and progression-free survival of patients with organ-confined disease were significantly greater than those of patients with T4 disease or lymph node metastasis. In addition, both survivals of patients with histologically confirmed UC tumors were greater than those of patients with non-UC tumors.

Radical cystectomy group. We investigated the significance of each factor, including pre-treatment clinical T-stage, pathological T-stage (pT4 vs. others), pathological N-stage, tumor pathology (non-UC vs. UC), patient performance status, gender, age and chemotherapy, as a predictor of progression- 
Table VI. Predictors of survival (PFS and OS) in the OMCregimen group evaluated by univariate and multivariate Cox regression analyses.

\section{A, Univariate Cox regression analysis}

\begin{tabular}{|c|c|c|c|c|}
\hline \multirow[b]{2}{*}{ Category } & \multicolumn{2}{|c|}{ PFS } & \multicolumn{2}{|c|}{ OS } \\
\hline & $\begin{array}{c}\text { Hazard } \\
\text { ratio }\end{array}$ & $\mathrm{P}$-value & $\begin{array}{c}\text { Hazard } \\
\text { ratio }\end{array}$ & P-value \\
\hline \multicolumn{5}{|l|}{ T-stage } \\
\hline T4 vs. T2-3 & 15.38 & $<0.0001$ & 10.99 & 0.0001 \\
\hline \multicolumn{5}{|l|}{ N-stage } \\
\hline $\mathrm{N}^{+}$vs. $\mathrm{N}^{-}$ & 9.174 & $<0.0001$ & 8.547 & 0.0004 \\
\hline \multicolumn{5}{|l|}{ Pathology } \\
\hline Non-UC vs. UC & 6.993 & 0.0004 & 7.194 & 0.0005 \\
\hline \multicolumn{5}{|l|}{ Performance status } \\
\hline 2 vs. $0-1$ & 1.112 & 0.8545 & 1.222 & 0.7388 \\
\hline \multicolumn{5}{|l|}{ Gender } \\
\hline Male vs. female & 1.196 & 0.7301 & 1.049 & 0.9362 \\
\hline \multicolumn{5}{|l|}{ Age } \\
\hline Cont. variable & 1.033 & 0.4934 & 1.086 & 0.1338 \\
\hline \multicolumn{5}{|c|}{ Amount of CDDP (mg) } \\
\hline 100 vs. 200 or 300 & 1.003 & 0.2661 & 2.840 & 0.1389 \\
\hline
\end{tabular}

$\mathrm{B}$, Multivariate Cox regression analysis

\begin{tabular}{|c|c|c|c|c|}
\hline \multirow[b]{2}{*}{ Category } & \multicolumn{2}{|c|}{ PFS } & \multicolumn{2}{|c|}{ OS } \\
\hline & $\begin{array}{c}\text { Hazard } \\
\text { ratio }\end{array}$ & P-value & $\begin{array}{c}\text { Hazard } \\
\text { ratio }\end{array}$ & P-value \\
\hline \multicolumn{5}{|l|}{ T-stage } \\
\hline T4 vs. T2-3 & 18.87 & 0.0003 & 4.525 & 0.1029 \\
\hline \multicolumn{5}{|l|}{ N-stage } \\
\hline $\mathrm{N}^{+}$vs. $\mathrm{N}^{-}$ & 6.623 & 0.0140 & 4.717 & 0.0921 \\
\hline \multicolumn{5}{|l|}{ Pathology } \\
\hline Non-UC vs. UC & 3.484 & 0.1259 & 3.205 & 0.1970 \\
\hline \multicolumn{5}{|l|}{ Performance status } \\
\hline 2 vs. $0-1$ & 4.663 & 0.0611 & 3.479 & 0.2051 \\
\hline \multicolumn{5}{|l|}{ Gender } \\
\hline Male vs. female & 3.739 & 0.0474 & 1.834 & 0.3964 \\
\hline \multicolumn{5}{|l|}{ Age } \\
\hline Cont. variable & 1.002 & 0.7748 & 1.091 & 0.0761 \\
\hline \multicolumn{5}{|c|}{ Amount of CDDP (mg) } \\
\hline 100 vs. 200 or 300 & 3.788 & 0.1216 & 1.402 & 0.7091 \\
\hline
\end{tabular}

PFS, progression-free survival; OS, overall survival; Cont. variable, continuous variable.

free and overall survival using the Cox regression model (Table VII). As shown in Table VII, univariate Cox regression analyses selected gender and histology as significant factors affecting progression-free and overall survival, respectively. Moreover, multivariate Cox regression analysis selected histology as a significant factor affecting both the overall and progression-free survival.

Survival comparison between groups at each clinical stage. Fig. 6 shows the Kaplan-Meier curves for the overall and
Table VII. Predictors of survival (PFS, OS) in the total cystectomy group evaluated by univariate and multivariate Cox regression analyses.

A, Univariate Cox regression analysis

\begin{tabular}{|c|c|c|c|c|}
\hline \multirow[b]{2}{*}{ Category } & \multicolumn{2}{|c|}{ PFS } & \multicolumn{2}{|c|}{ OS } \\
\hline & $\begin{array}{c}\text { Hazard } \\
\text { ratio }\end{array}$ & P-value & $\begin{array}{c}\text { Hazard } \\
\text { ratio }\end{array}$ & P-value \\
\hline \multicolumn{5}{|l|}{ Clinical T-stage } \\
\hline $\mathrm{T} 3$ vs. Cis or $\mathrm{T} 2$ & 1.447 & 0.5205 & 1.642 & 0.4010 \\
\hline \multicolumn{5}{|c|}{ Pathological T-stage } \\
\hline pT4 vs. others & 2.247 & 0.2430 & 1.748 & 0.4185 \\
\hline \multicolumn{5}{|c|}{ Pathological N-stage } \\
\hline $\mathrm{N}^{+}$vs. $\mathrm{N}^{-}$ & 1.339 & 0.7105 & 1.209 & 0.8110 \\
\hline \multicolumn{5}{|l|}{ Histology } \\
\hline Non-UC vs. UC & 1.335 & 0.6381 & 11.24 & 0.0220 \\
\hline \multicolumn{5}{|l|}{ Performance status } \\
\hline $0-1$ vs. 2 & 1.369 & 0.6094 & 1.395 & 0.6049 \\
\hline \multicolumn{5}{|l|}{ Gender } \\
\hline Male vs. female & 20.423 & 0.0028 & 3.338 & 0.1297 \\
\hline \multicolumn{5}{|l|}{ Age } \\
\hline Cont. variable & 1.117 & 0.3138 & 1.143 & 0.2727 \\
\hline \multicolumn{5}{|l|}{ Chemotherapy } \\
\hline (+) vs. (-) & 1.149 & 0.4648 & 1.890 & 0.2585 \\
\hline
\end{tabular}

$\mathrm{B}$, Multivariate Cox regression analysis

\begin{tabular}{|c|c|c|c|c|}
\hline \multirow[b]{2}{*}{ Category } & \multicolumn{2}{|c|}{ PFS } & \multicolumn{2}{|c|}{ OS } \\
\hline & $\begin{array}{c}\text { Hazard } \\
\text { ratio }\end{array}$ & P-value & $\begin{array}{c}\text { Hazard } \\
\text { ratio }\end{array}$ & P-value \\
\hline \multicolumn{5}{|l|}{ Clinical T-stage } \\
\hline $\mathrm{T} 3$ vs. Cis or $\mathrm{T} 2$ & 2.841 & 0.3858 & 2.017 & 0.1984 \\
\hline \multicolumn{5}{|c|}{ Pathological T-stage } \\
\hline pT4 vs. others & 1.042 & 0.1089 & 9.174 & 0.1466 \\
\hline \multicolumn{5}{|c|}{ Pathological N-stage } \\
\hline $\mathrm{N}^{+}$vs. $\mathrm{N}^{-}$ & 2.242 & 0.4704 & 2.137 & 0.5126 \\
\hline \multicolumn{5}{|l|}{ Histology } \\
\hline Non-UC vs. UC & 111.1 & 0.0181 & 200.0 & 0.0092 \\
\hline \multicolumn{5}{|l|}{ Performance status } \\
\hline 2 vs. $0-1$ & 1.115 & 0.8860 & 1.713 & 0.5180 \\
\hline \multicolumn{5}{|l|}{ Gender } \\
\hline Male vs. female & 24.338 & 0.0180 & 2.017 & 0.4556 \\
\hline \multicolumn{5}{|l|}{ Age } \\
\hline Cont. variable & 1.134 & 0.3942 & 1.095 & 0.5424 \\
\hline \multicolumn{5}{|l|}{ Chemotherapy } \\
\hline$(+)$ vs. (-) & 2.188 & 0.3228 & 2.036 & 0.3287 \\
\hline
\end{tabular}

PFS, progression-free survival; OS, overall survival; Cont. variable, continuous variable.

progression-free survival of patients at each clinical stage (T2, Fig. 6A and B; T3, Fig. 6C and D) in both groups. For stage $\mathrm{T} 3$, both the overall and progression-free survival were significantly greater in the OMC-regimen than in the cystectomy group. 
A

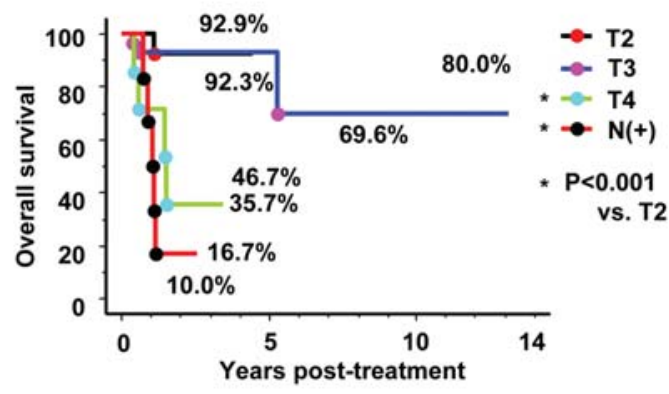

B

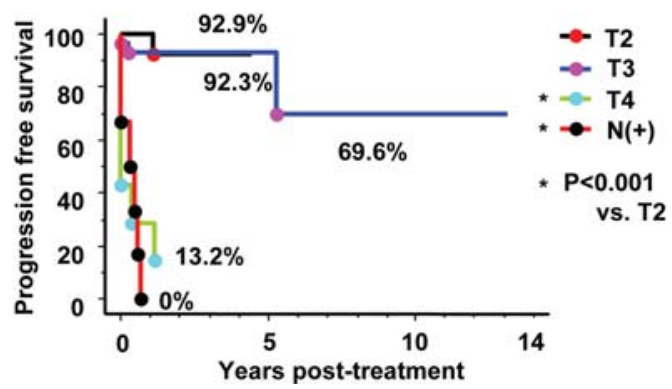

C

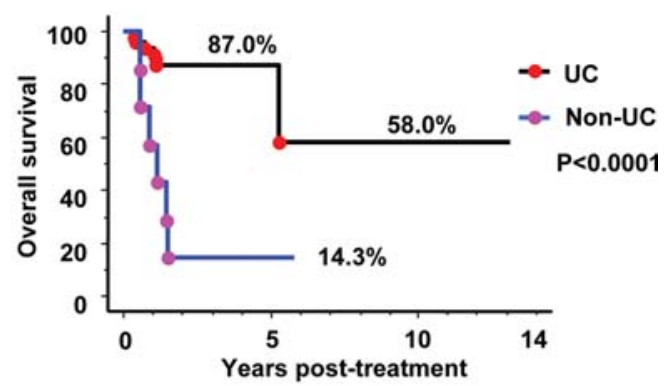

D

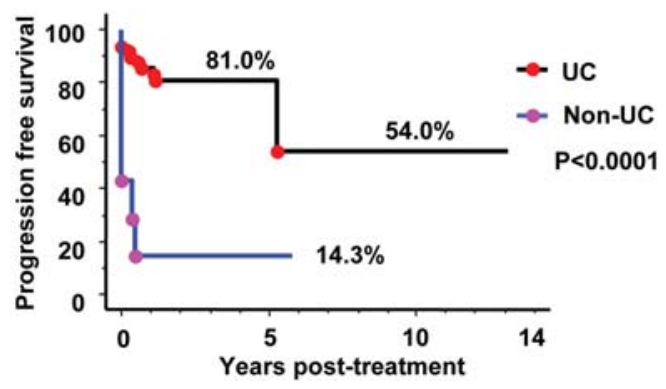

Figure 5. Kaplan-Meier curves for overall and progression-free survival of patients treated with the OMC-regimen at each clinical stage (A and B) and for each histological type (C and D), respectively. Both the overall and progression-free survival of patients with organ-confined disease were significantly greater than those of patients with T4 disease or with lymph node metastasis. Both survivals of patients with histologically proven UC tumors were also greater than those of patients with non-UC tumors.

A

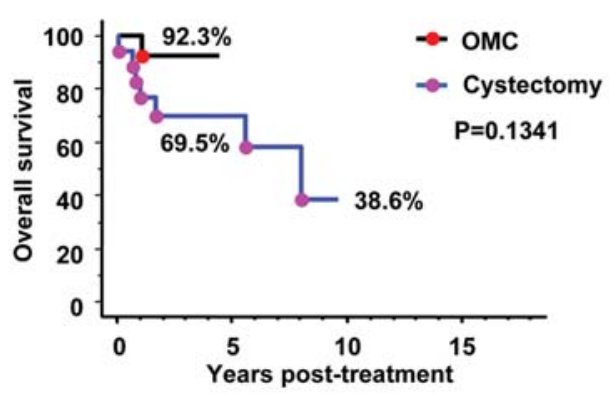

B

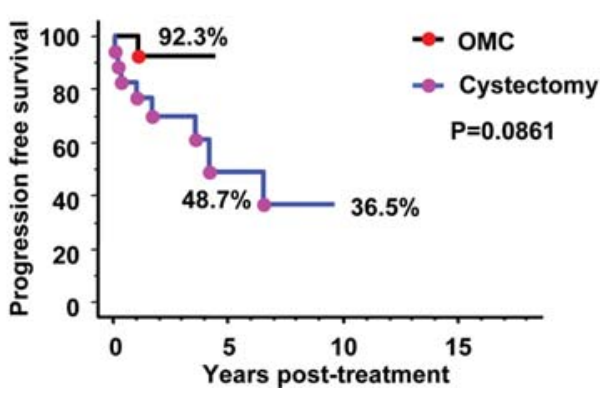

C

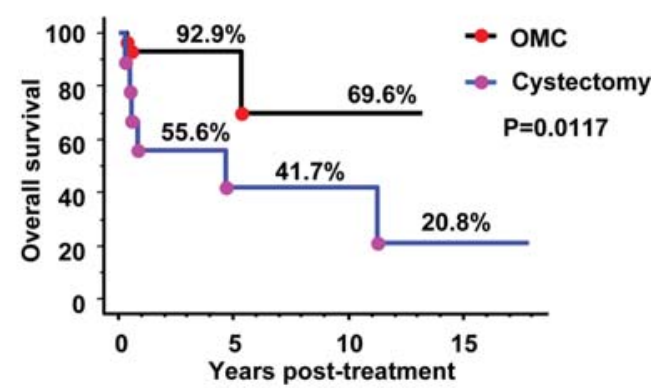

D

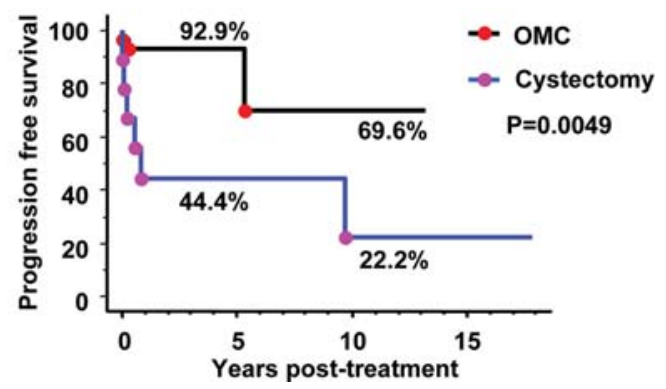

Figure 6. Kaplan-Meier curves for overall and progression-free survival of patients at each clinical stage (T2, A and B; T3, C and D) in both groups. Both the overall and progression-free survival of the stage $\mathrm{T} 3$ patients in the OMC-regimen group were significantly greater than those of patients in the cystectomy group.

Toxicity. The most significant outcome of the OMC-regimen was that its related toxicities were markedly less severe than those reported by other clinical trials, as shown in Table VIII.
None of the patients suffered grade III or more severe toxicities. Certain patients experienced grade I blood/bone marrow toxicity (5 patients, $8.93 \%$; $95 \%$ CI, 2.96-19.6\%), 
Table VIII. Toxicity.

\begin{tabular}{|c|c|c|c|c|c|c|}
\hline \multirow[b]{3}{*}{ Toxicity } & \multicolumn{3}{|c|}{ Grade } & \multicolumn{3}{|c|}{ Duration (days) } \\
\hline & 1 & 2 & $3-4$ & $<3$ & $3-7$ & $>7$ \\
\hline & No. $(\%)$ & No. $(\%)$ & No. $(\%)$ & No. $(\%)$ & No. $(\%)$ & No. $(\%)$ \\
\hline \multicolumn{7}{|l|}{ Blood/bone marrow } \\
\hline Total & $5(8.93)$ & 0 & 0 & 0 & $4(7.14)$ & $1(1.79)$ \\
\hline Granulocytopenia & $4(7.14)$ & 0 & 0 & 0 & $3(5.36)$ & $1(1.79)$ \\
\hline Anemia & $4(7.14)$ & 0 & 0 & 0 & $3(5.36)$ & $1(1.79)$ \\
\hline \multicolumn{7}{|l|}{ Gastrointestinal } \\
\hline Total & $14(25.0)$ & 0 & 0 & 0 & 0 & 0 \\
\hline Anorexia & $9(16.1)$ & 0 & 0 & $2(3.57)$ & $7(12.5)$ & 0 \\
\hline Constipation & $5(8.93)$ & 0 & 0 & $1(1.79)$ & $4(7.14)$ & 0 \\
\hline Diarrhea & $7(12.5)$ & 0 & 0 & $4(7.14)$ & $3(5.36)$ & 0 \\
\hline Nausea & $11(19.6)$ & 0 & 0 & $8(14.3)$ & $3(5.36)$ & 0 \\
\hline Vomiting & $2(1.79)$ & 0 & 0 & $1(1.79)$ & $1(1.79)$ & 0 \\
\hline Neuropathy & $1(1.79)$ & 0 & 0 & 0 & 0 & $1(1.79)$ \\
\hline
\end{tabular}

Table IX. Removal ratio of CDDP by HD.

\begin{tabular}{lccccccc}
\hline & \multicolumn{3}{c}{ Free-platinum concentration } & & \multicolumn{3}{c}{ Total-platinum concentration } \\
\cline { 2 - 3 } Time (min) & Pre-HD $(\mu \mathrm{g} / \mathrm{ml})$ & Post-HD $(\mu \mathrm{g} / \mathrm{ml})$ & Removal ratio $(\%)$ & & Pre-HD $(\mu \mathrm{g} / \mathrm{ml})$ & Post-HD $(\mu \mathrm{g} / \mathrm{ml})$ & Removal ratio $(\%)$ \\
\hline 30 & $2.42 \pm 0.31$ & $0.10 \pm 0.03$ & $95.7 \pm 1.65$ & & $4.05 \pm 0.18$ & $1.42 \pm 0.41$ & $65.3 \pm 8.81$ \\
60 & $2.91 \pm 0.54$ & $0.12 \pm 0.05$ & $95.5 \pm 2.57$ & & $5.43 \pm 0.58$ & $1.91 \pm 0.87$ & $65.9 \pm 12.6$ \\
120 & $\mathrm{ND}$ & $\mathrm{ND}$ & $\mathrm{ND}$ & & $1.76 \pm 0.23$ & $1.12 \pm 0.16$ & $36.3 \pm 3.30$ \\
\hline
\end{tabular}

ND indicates levels below the detection limit.

gastrointestinal toxicity (14 patients, $25 \%$; 95\%CI, 14.4$38.4 \%$ ) or neuropathy ( 1 patients, $1.79 \%$; $95 \%$ CI, 0.05 $9.55 \%)$. The duration of blood/bone marrow toxicity, including granulocytopenia and anemia, was relatively short: Median duration was 6 days (range, 5-9 days) for granulocytopenia, and 5 days (range, 3-10 days) for anemia. No patients were treated with the granulocyte colony-stimulating factor or the transfusion of red blood cells. Gastrointestinal toxicity included anorexia in 9 patients $(16.1 \%$; $95 \% \mathrm{CI}$, 7.62-28.3\%), constipation in 5 (8.93\%; 95\% CI, 2.96-19.6\%), diarrhea in $7(12.5 \%$; $95 \% \mathrm{CI}, 5.18-24.1 \%)$, nausea in 11 $(19.6 \%$; $95 \% \mathrm{CI}, 10.2-32.4 \%)$, and vomiting in $2(3.57 \%$; $95 \%$ CI, $0.44-12.3 \%$ ), but all symptoms disappeared within 4 days after intra-arterial infusion. With regards to renal function, certain patients showed an increase of $>20 \%$ in peak serum creatinine levels, 7 days after intra-arterial infusion, but this returned to previous levels after 14 days in all patients. In other patients, however, we found no significant differences in BUN or serum creatinine levels before or after intra-arterial infusion. There were no other adverse reactions such as genitourinary toxicity, radiation cystitis or life-threatening complications.
Cisplatin removal ratio. We measured the concentrations of serum-free (protein-unbound) platinum and serum-total (protein-unbound + protein-bound) platinum in the blood draining from the common iliac veins (before HD) as well as in the blood returning to the vena cava (after HD) at 30, 60 and 120 min after initiation of HD. We calculated the ratio of serum-free as well as serum-total platinum removed by HD at each time-point. Over $95 \%$ of protein-unbound platinum was efficiently removed from the blood by HD while the intra-arterial infusion of CDDP was performed (within $60 \mathrm{~min}$ after the initiation of BOAI), and the concentration of serumfree platinum decreased to below the detection limit within 120 min after the start of HD (Table IX). Though the removal ratio was not as high as that of serum-free platinum, $>65 \%$ of total platinum was eliminated during BOAI with CDDP.

\section{Discussion}

The gold standard of therapy for locally invasive bladder cancer (T2-4, N0M0) is radical cystectomy. However, $80 \%$ of bladder cancer cases are diagnosed in individuals over the age of 60 (13). Many of these patients could be at risk of 
various conditions such as heart and lung disease (14), and are therefore deemed poor candidates for surgery due to their medical co-morbidities.

BOAI allows for the delivery of an extremely high concentration of anti-cancer agent to the bladder and surrounding pelvic region (15-17). In addition, severe hypoxia in the target region resulting from BOAI, could play a role in the marked anti-tumor effect, as several basic studies have demonstrated that hypoxia greatly enhances the effectiveness of CDDP $(18,19)$. The enhanced radiosensitivity of the cancer cells due to the BOAI-induced high concentration of CDDP could also contribute significantly to the good response achieved. CDDP is a well-known radiosensitizer, which facilitates cell death by inhibiting the repair of radiotherapyinduced DNA damage, and/or can damage genes known to be related to radiosensitivity, e.g., BRCA2, and hMLH1, thereby enhancing radiosensitivity and eventually triggering apoptosis (18-21). These factors are likely be responsible for the better outcome achieved with the OMC-regimen as opposed to cystectomy.

The other advantage of the OMC-regimen, especially for elderly patients, is the significant reduction in systemic sideeffects. CDDP exerts its anti-tumor activity via the nonprotein-bound form, which reduces steeply after administration: Its half-life is normally $<60 \mathrm{~min}$, and reaches to below the detection limit $4 \mathrm{~h}$ after administration $(22,23)$. The most important factor of the OMC-regimen is the removal of non-protein-bound platinum immediately after the administration of CDDP by performing HD via the bilateral common iliac veins, which accomplishes the efficient drainage of CDDP immediately after passage through the tumor. HD is specifically efficient for CDDP elimination, as the molecular weight of protein-unbound CDDP is $\sim 300$, similar to that of creatinine. Moreover, the anatomical structure and blood supply of the bladder could largely account for the efficient drainage of CDDP achieved with this approach. As the urinary bladder is situated at the base of the pelvis, the relatively close circuit formed by the internal iliac artery, bladder, and common iliac veins, could contribute to the efficient drainage of the anti-cancer agent, thus increasing the elimination efficiency without influencing the systemic circulation. Indeed, we found that $>95 \%$ of serumfree platinum was efficiently eliminated by HD during BOAI with CDDP, thus providing optimal conditions for the effective local accumulation of platinum in the tumor, with minimal systemic toxicity, and therefore allowing the 98year-old patients to complete this regimen.

As further experience is acquired in the application of this treatment, it is clear that future studies will focus on the proper selection of patients who will most probably benefit from it, and/or who are not eligible due to clinical background factors. The predictive factors selected on the basis of the present results will be useful for improving the efficacy of treatment and yielding more satisfactory outcomes. Clinical stage is one of the most important predictive factors of the outcome for this therapy. More than 90\% (39/43) of patients with locally invasive tumors achieved $\mathrm{CR}$, and none of them developed recurrence, while most patients with stage T4 tumors and/or lymph node metastasis showed disappointing outcomes. Our results indicate that patients with organ- confined tumors are more promising candidates for this treatment. The histological type of the tumor, i.e. UC or non$\mathrm{UC}$, is another important determinant of treatment outcome. Of the 56 patients who received the OMC-regimen, all patients who achieved CR had UC tumors, whereas the response was rated as partial disease or disease recurrence in the other patients with non-UC tumors.

Thus, the OMC-regimen, which delivers an extremely high concentration of anti-cancer agent to the site of a tumor without causing systemic adverse effects, can be regarded as a curative therapy for elderly patients, not only for those for whom total cystectomy has been indicated, but also for those for whom total cystectomy is not feasible due to age, performance status or other reasons and who are considered physically incapable of tolerating the chemotherapeutic regimens that are usually applied clinically. This therapy could improve the feasibility of radical cure without the need for cystectomy in patients for whom such surgery would otherwise be necessary, and could also lead to a potential cure for patients whose condition would normally have ruled out such a possibility and for whom, otherwise, merely palliative treatment would have been the only option.

\section{References}

1. Tran E, Souhami L, Tanguay S and Rajan R: Bladder conservation treatment in the elderly population: results and prognostic factors of muscle-invasive bladder cancer. Am J Clin Oncol 32: 333-337, 2009

2. Weizer AZ, Joshi D, Daignault S, et al: Performance status is a predictor of overall survival of elderly patients with muscle invasive bladder cancer. J Urol 177: 1287-1293, 2007.

3. Hoshi S, Shintaku I, Suzuki K, et al: Bladder preservation by internal iliac arterial infusion chemotherapy and irradiation in T3 bladder carcinoma patients over the age of 70 years. Tohoku J Exp Med 192: 249-258, 2000.

4. Kaufman DS, Winter KA, Shipley WU, et al: The initial results in muscle-invading bladder cancer of RTOG 95-06: phase I/II trial of transurethral surgery plus radiation therapy with concurrent CDDP and 5-fluorouracil followed by selective bladder preservation or cystectomy depending on the initial response. Oncologist 5: 471-476, 2000.

5. Rodel C, Grabenbauer GG, Kuhn R, et al: Combined-modality treatment and selective organ preservation in invasive bladder cancer: long-term results. J Clin Oncol 20: 3061-3071, 2002.

6. Nielsen ME, Shariat SF, Karakiewicz PI, et al: Advanced age is associated with poorer bladder cancer-specific survival in patients treated with radical cystectomy. Eur Urol 51: 698-706, 2007.

7. Shipley WU, Winter KA, Kaufman DS, et al: Phase III trial of neoadjuvant chemotherapy in patients with invasive bladder cancer treated with selective bladder preservation by combined radiation therapy and chemotherapy: initial results of Radiation Therapy Oncology Group 89-03. J Clin Oncol 16: 3576-3583, 1998.

8. Tester W, Caplan R, Heaney J, et al: Neoadjuvant combined modality program with selective organ preservation for invasive bladder cancer: results of Radiation Therapy Oncology Group phase II trial 8802. J Clin Oncol 14: 119-126, 1996.

9. Shipley WU, Prout GRJ, Einstein AB, et al: Treatment of invasive bladder cancer by cisplatin and radiation in patients unsuited for surgery. JAMA 258: 931-935, 1987.

10. Hagan MP, Winter KA, Kaufman DS, et al: RTOG 97-06: initial report of a phase I-II trial of selective bladder conservation using TURBT, twice-daily accelerated irradiation sensitized with cisplatin, and adjuvant MCV combination chemotherapy. Int J Radiat Oncol Biol Phys 57: 665-672, 2003.

11. Greene FL, Page DL and Fleming ID: AJCC cancer staging manual. 6th edition. Springer Verlag, New York, 2002.

12. Ficcara V, Dalpiaz O, Alrabi N, Novara G, Galfano A and Artibani W: Correlation between clinical and pathological staging in a series of radical cystectomies for bladder carcinoma. BJU Int 95: 786-790, 2005. 
13. Jemal A, Siegel R, Ward E, Hao Y, Xu J and Thun MJ: Cancer statistics, 2009. CA Cancer J Clin 59: 225-249, 2009.

14. Johansson SL and Cohen SM: Epidemiology and etiology of bladder cancer. Semin Surg Oncol 13: 291-298, 1997.

15. Collins JM: Pharmacokinetic rationale for intraarterial therapy. In: Cancer Chemotherapy, Challenges for the Future. Kimura K (ed). Vol. 4. Excepta Medica, Amsterdam, 1989.

16. Mitsuzane K, Kawabata M, Terada M, Nomura S, Sato M and Yamada R: Balloon-occluded arterial infusion as chemotherapy in bladder cancer - long-term results. Gan To Kagaku Ryoho 17: 1701-1704, 1990.

17. Cvitkovic E, Spaulding J, Bethune V, Martin J and Whitmore WF: Improvement of cis-dichlorodiammineplatinum (NSC 119875): therapeutic index in an animal model. Cancer 39: 1357-1361, 1977.

18. Douple EB and Richmond RC: A review of platinum complex biochemistry suggests a rationale for combined platinumradiotherapy. Int J Radiat Oncol Biol Phys 8: 1335-1339, 1979.
19. Abbott DW, Freeman ML and Holt JT: Double-strand break repair deficiency and radiation sensitivity in BRCA2 mutant cancer cells. J Natl Cancer Inst 90: 978-985, 1998.

20. Brown JM and Wouters BG: Apoptosis, p53, and tumor cell sensitivity to anticancer agents. Cancer Res 59: 1391-1399, 1999.

21. Chadwick KH, Leenhouts HP, Szumiel I and Nias AH: An analysis of the interaction of a platinum complex and radiation with CHO cells using the molecular theory of cell survival. Int J Radiat Biol Relat Stud Phys Chem Med 6: 511-524, 1976.

22. Belt RJ, Himmelstein KJ, Patton TF, Bannister SJ, Sternson LA and Repta AJ: Pharmacokinetics of non-protein-bound platinum species following administration of cis-dichlorodiammineplatinum (II). Cancer Treat Rep 63: 1515-1521, 1979.

23. Himmelstein KJ, Patton TF, Belt RJ, Taylor S, Repta AJ and Sternson LA: Clinical kinetics on intact cisplatin and some related species. Clin Pharmacol Ther 29: 658-664, 1981. 